\title{
UPSTAIRS, DOWNSTAIRS: COMPUTER-SKILL COMPLEMENTARITY AND COMPUTER-LABOR SUBSTITUTION ON TWO FLOORS OF A LARGE BANK
}

\author{
David H. Autor \\ Frank Levy \\ Richard J. Murnane \\ Working Paper 7890 \\ http://www.nber.org/papers/w7890 \\ NATIONAL BUREAU OF ECONOMIC RESEARCH \\ 1050 Massachusetts Avenue \\ Cambridge, MA 02138 \\ September 2000
}

MIT Department of Economics and NBER, MIT Department of Urban Studies and Planning, and Harvard Graduate School of Education and NBER respectively. The Russell Sage and Sloan Foundations supported the research on which this paper is based. The views expressed herein are those of the authors and not necessarily those of the National Bureau of Economic Research.

(C) 2000 by David H. Autor, Frank Levy, and Richard J. Murnane. All rights reserved. Short sections of text, not to exceed two paragraphs, may be quoted without explicit permission provided that full credit, including (C) notice, is given to the source. 
Upstairs, Downstairs: Computer-Skill Complementarity and

Computer-Labor Substitution on Two Floors of a Large Bank

David H. Autor, Frank Levy, and Richard J. Murnane

NBER Working Paper No. 7890

September 2000

JEL No. J3, O3

\begin{abstract}
We describe how a single technological innovation, the introduction of image processing of checks, led to distinctly different changes in the structure of jobs in two departments of a large bank overseen by one group of managers. In the downstairs deposit processing department, image processing led to the substitution of computers for high school educated labor in accomplishing core tasks and in greater specialization in the jobs that remained. In the upstairs exceptions processing department, image processing led to the integration of tasks, with an associated increase in the demand for particular skills. The case illustrates the interdependence of technological change and organizational change. It suggests that 'seeing the whole picture' and associated conceptual and problem-solving skills are made more valuable by information technologies. Finally, it underscores that the short-term consequences of technological changes may depend importantly on regulatory forces.
\end{abstract}

\author{
David H. Autor \\ Frank Levy \\ Department of Economics \\ Department of Economics \\ MIT, E52-380B \\ MIT \\ 50 Memorial Drive \\ 50 Memorial Drive \\ Cambridge, MA 02142 \\ Cambridge, MA 02142 \\ and NBER \\ flevy@mit.edu \\ dautor@mit.edu \\ Richard Murnane \\ Graduate School of Education \\ Harvard University \\ 6 Appian Way - Gutman 409 \\ Cambridge, MA 02138 \\ and NBER \\ richard_murnane@harvard.edu
}


A number of recent studies have documented a strong association between the use of computers $^{1}$ and the use of more educated labor in production. These associations appear across detailed industries and across plants within industries in the U.S., ${ }^{2}$ as well as in data from other industrialized countries. ${ }^{3}$ The explanation of this pattern favored by economists is computer-skill complementarity or skill-biased technological change: technological change involving computers that increases the productivity of highly educated workers more than it increases the productivity of less-educated workers. An alternative explanation popularized in books such as The End of Work (Rifkin, 1995) is computer-labor substitution: computers substitute for low skilled labor in carrying out a variety of tasks. ${ }^{4}$

While both of these potentially complementary explanations have intuitive validity, they raise immediate questions: What are the skills that computers complement? What are the set of worker tasks for which they substitute? In this paper we describe how these questions were answered when a particular technological change was introduced to two back office departments of Cabot Bank, a large commercial bank. ${ }^{5}$ We show that the same technological change, the introduction of image processing of checks, led to quite different changes in the structure of jobs in two departments overseen by the same group of managers. In the downstairs department, deposit processing, image processing led to the direct substitution of computers for high school educated labor in accomplishing several core tasks, as well as greater specialization in the jobs

\footnotetext{
${ }^{1}$ Throughout the paper, we use the term computerization broadly to include the internet, digital imaging, etc. as well as computers per se.

${ }^{2}$ See, for example, (Autor, Katz and Krueger, 1998), (Berman, Bound and Griliches, 1994) (Bresnahan, Brynjolfsson and Hitt, 1999), and (Wolff, 1996).

${ }^{3}$ See, for example, (Berman, Bound and Machin, 1998) and (Machin and Van Reenen, 1998).

${ }^{4}$ In net, both raise relative demand for highly skilled workers. Nevertheless, they are conceptually distinct and hold different implications for wage growth.

${ }^{5}$ The name Cabot Bank is fictitious.
} 
that remained. In the upstairs department, exceptions processing, image processing led to the integration of tasks, with an associated increase in the demand for particular skills.

Case studies, of course, cannot yield economy-wide relationships. However, by providing details about the impacts of particular technological changes in specific settings, they can animate theoretical notions of computer-skill complementary and computer-labor substitution and stimulate hypotheses to structure empirical work. ${ }^{6}$

Banking has two advantages as a site for a case study of computerization. Traditionally, a significant fraction of banking and financial services jobs have been held by workers with no post-secondary education - the group whose earnings have not fared well over the last 20 years (Katz and Murphy, 1992). In addition, the banking industry has experienced dramatic technological change through computerization over a half-century (Mayer, 1997).

In the next section we provide a framework for our case study by discussing what tasks computers typically perform and how they may influence skill demands, both through task substitution and skill complementarity. Section 3 describes how the introduction of image processing influenced the structure of employment and skill demands in Cabot bank's deposit processing department. Section 4 describes the impact of image processing on the organization of work and on skill demands in the bank's exceptions processing department. The concluding section of the paper summarizes our findings and suggests lessons from the paper.

\section{What Computers Do: A Task Framework}

To understand computerization's impact on skill demands, it is useful to conceptualize work as performing a set of tasks. ${ }^{7}$ Examples include recording the value of a check in a ledger,

\footnotetext{
${ }^{6}$ This point is well articulated by (Feldstein, 2000). For an example, see our companion empirical paper to this case, (Autor, Levy and Murnane, 2000).

${ }^{7}$ Thanks go to Randy Davis of MIT's Artificial Intelligence Lab and Pete Szolovits of MIT's Laboratory for Computer Science for helpful conversations.
} 
resolving a processing error, and mediating a customer grievance. In this context, we ask the question: which tasks can be performed by a computer?

An initial answer to this question is that computers can perform tasks than can be fully described as a series of logical programming commands ("If-Then-Do") that designates what actions the machine will perform and in what sequence at each contingency. As the price of computing declines, the range of tasks accomplished by computers grows. These tasks currently include not only bookkeeping and filing, but also searching the web efficiently for information relevant to a particular question, determining people's tastes in books and music (via 'data mining'), and detecting fraudulent financial transactions by 'observing' aberrant purchases of products or services.

Although computers directly substitute for a variety of human tasks, they often accomplish these tasks quite differently from the ways humans would, and sometimes do not provide identical services - for example, automatic teller machines (ATMs) do not provide the personal interactions that some customers want from tellers. However, they do accomplish the essential tasks that most banking customers want, and do so much more rapidly than tellers and at less expense. They accomplish these tasks through machinery directed by a computer program that is expressed as a series of if-then, do statements. Following such a set of well-defined instructions expressed in computer code is the common feature of the tasks accomplished commercially by computers today.

While the range of tasks accomplished by computers is growing, it is important to recognize that humans accomplish many tasks quite readily that will not be computerized quickly. The reason is summarized succinctly by Michael Polyani's observation that, "We do not know how to do many of the things we do" (Polanyi, 1966). For example, many commonplace manual tasks 
such as cleaning a room or driving a truck have proven surprisingly difficult to automate.

Completion of these tasks appears to requires optical recognition and adaptive fine motor control that at present are poorly understood and consequently cannot (yet) be described by a computer program (Pinker, 1997). There are other interactive tasks that some humans do well, such as mediating disputes and gaining the trust of customers or subordinates, that are also very difficult to describe as a sequence of if-then-do steps. These tasks are also not likely candidates for computerization in the near future.

A second limit on the tasks computers perform arises because computer programs expressed in if-then-do logic can normally only address "known" problems: contingencies unanticipated by the programmer will typically result in a dead-end. ${ }^{8}$ For this reason, computers cannot at present readily carry out many of the cognitive and analytic tasks that managers and professionals routinely tackle. Examples include identifying and solving ill-posed problems, developing cogent arguments, and finding methods to improve production processes. Computers do, however, increase the productivity of skilled workers in accomplishing these tasks by increasing informational inputs, speeding search and retrieval, enabling rapid quantitative analysis, and facilitating extensive monitoring of workers and production processes (Zuboff, 1988). Through these mechanisms, computers appear to complement skilled workers in these tasks. ${ }^{9}$

This set of observations may be useful in understanding how a computer-based technological change influenced how work was organized and accomplished in two departments of Cabot Bank - one upstairs, and one downstairs.

\footnotetext{
${ }^{8}$ That is, the problem remains unsolved but the diagnostic rules offer no more alternatives. For examples of such diagnostic dead ends, see Orr (1996) and Levy, Beamish et. al (1999).

${ }^{9}$ This strong complementarity is discussed at greater length in Autor, Levy, and Murnane (2000).
} 


\section{Deposit Processing in Cabot Bank}

"Cabot Bank" is one of the 20 largest banks in the United States. It has both large retail and large commercial banking operations, with branches in several states and in many countries outside the United States. The retail part of Cabot Bank has more than doubled its size over the last decade, primarily through acquisitions of smaller banks.

Our first description deals with Cabot Bank's deposit processing services, the first-floor back office department that processes the 2.8 million checks deposited in the bank's branches and automatic teller machines each day. The steps that Cabot Bank must complete to process customers' deposits have not changed markedly since checks were introduced in the United States shortly after the Civil War. It must record ("capture") the amounts of individual checks, "proof the deposit" - that is, verify that the sum of the values of checks deposited by a customer is equal to the amount indicated on the customer's deposit slip - and then post the balance to the appropriate account. The bank then separates the checks into those written by customers of the bank ("on us") and those written on other banks (transit items). It debits the "on us" checks to the appropriate account and delivers the checks written on other banks to those banks as quickly as possible so to minimize float.

\section{a. The Paper-Based System}

Fifty years ago Cabot Bank and its competitors did all of the sorting, proofing, balancing, and posting by hand with the aid of mechanical adding machines. The first major wave of technological change was the Bank of America's introduction of Magnetic Ink Character Recognition (MICR) in the early 1950s. Using MICR, a bank could provide its customers with checks and deposit slips with bank and account numbers imprinted at the bottom of the check in machine-readable magnetic ink. Companies including General Electric, Remington, and IBM developed reader-sorter machines that could read the information on the MICR line and sort 
checks according to the banks on which they were drawn (McKenney, 1995). This

reading/sorting was an early example of computers substituting for people in performing a task

that could be accomplished by equipment following a set of if- then- do instructions expressed in software.

Over the next fifty years MICR machines increased in speed but the work organization of deposit processing was remarkably stable and centered on the position of the proofing machine operator. As an example, the Cabot Bank processing center would receive a package of several hundred checks from K-Mart. The package would include a deposit slip and an adding machine tape to show that the checks had been totaled correctly. The proofing machine operator would then execute the following steps:

- Remove paper clips and staples from the checks and make sure all checks face in the same direction.

- Key in the amount of each check on the right hand side of the MICR line.

- Add up the total of the K-Mart checks and "proof" the deposit - i.e. verify that the checks total to the amount on the K-Mart deposit slip.

- If the total did not match the deposit slip, examine the adding machine tape and the encoded check amounts to find and correct the error. Possibilities include a keying error on the part of the proof machine operator, a listing error by the K-Mart employee who provided the adding machine tape, and a check lost in transit.

- Send the checks to the reader-sorter machine that would sort them by account number. ${ }^{10}$

\footnotetext{
${ }^{10}$ The proofing machine operator's large variety of tasks - removing staples, reading and keying in check values, discovering why deposits do not balance -- raises an obvious question: Why were these tasks bundled into a single job rather than assigned to separate workers? The question is underlined by the fact that the tasks have a natural sequence and so lend themselves to a division of labor. Moreover, accomplishing some of the tasks (balancing) requires skills not needed in carrying out other tasks (removing staples). We can speculate that someone who is particularly good at solving balancing problems would be more productive if they didn't have to spend time removing staples from checks. We lack a definitive answer to the question - the proofing operator's job was designed many years ago. But we suspect one reason for consolidating the tasks was to reduce transactions costs associated with moving paper checks from one employee to another. In Section III, we show that such transactions costs were a significant problem in the exceptions processing department, where tasks were separated.
} 
In a limited number of cases, the reader-sorter could not read the MICR line because the check was damaged. These unreadable checks were carried to operators of check repair machines who keyed in the MICR information on a strip of paper, attached the strip to the bottom of the check, and returned the check to be read and sorted.

\section{b. New Technology}

Over time, a set of forces was pushing Cabot Bank and its competitors to increase checkprocessing efficiency. The number of checks to be processed increased dramatically. ${ }^{11}$

Nonetheless, processing had to be done quickly. Federal Reserve Bank regulations mandated that customers have access to their deposits within a specified period of time (two days for checks drawn on local banks), but regulations also required a bank to return paper checks to the banks on which they were drawn in order to receive payment. Rapid processing was necessary to minimize the costs of float. In addition, banking deregulation had increased competitive pressure to reduce cost and respond to customer demands for new and improved services (Mayer, 1997).

To help address these pressures, Cabot Bank in 1994 introduced "imaging" into its deposit processing system. With imaging technology, a high-speed camera makes a digital image of the front and back of each check as it passes through the reader-sorter. The image is stored on a central computer and is then accessible to bank employees working at networked personal computers. As part of this innovation, the bank also adopted Optical Character Recognition (OCR) software to scan and capture the amounts on check images as the checks passed through the reader-sorter. Deposit slips were scanned in a similar way. Imaging was not a new

\footnotetext{
${ }^{11}$ Recall that Cabot Bank processed about 2.8 million checks per night in its central processing facility. U.S. banks in total process about 320 million checks a night and despite the increased use of electronic transfers, the Federal Reserve Bank projects that check volume in the U.S. will increase by one percent per year over the next 15 years.
} 
technology in the $1990 \mathrm{~s},{ }^{12}$ but Cabot Bank was one of the first banks to use the technology to balance deposits, a high volume daily activity that had to be completed under significant time pressure.

Computerized imaging and OCR could now accomplish significant parts of the proofing machine operator's job. It also offered the possibility of lowering the transactions costs of moving checks (now imaged, rather than paper) among people. Cabot used this potential to reorganize the workflow around a more extensive division of labor.

Under the new process, the check first goes to a preparation area where workers remove paper clips and staples and make sure that all the checks face in the same direction. These workers then deliver the checks to a reader-sorter machine that magnetizes the ink on the MICR line of the item, reads it, sprays an endorsement and sequence number on the back of the check, microfilms the item front and back, and sorts it to a program-defined pocket based upon the routing information on the check. As the checks pass through the reader-sorter, an image camera captures a digitized image of the front and back of the item. At the same time, OCR software scans machine-printed and handwritten numeric amounts in a designated location of the check. Successfully scanned information is stored along with the information on the MICR line of the check. As of 1999 the OCR software successfully "read" about 57 percent of imaged checks. ${ }^{13}$

When a digital dollar amount cannot be recognized, the image is sent first to the screen of a high speed keyer who tries to identify the check amount by looking at the numerical image written in the small line on the right side of the check. If the high speed keyer is not sure of the

\footnotetext{
${ }^{12}$ For example, lawyers and accountants were using it to make electronic copies of wills and estate documents ${ }^{13}$ The OCR software makes both Type I and Type II errors, in some cases misreading debit amounts, and in others rejecting as 'illegible' checks that were in fact correctly read. Type I errors are particularly costly because after they are caught by bank employees or customers they require laborious downstream correction. With these facts in mind, the bank 'tunes' the OCR software to minimize total check processing cost.
} 
amount from its numerical rendition he or she passes the check image electronically to a low speed keyer. This operator looks at the image of the whole check and by comparing the numerical representation to the amount written in words, determines the value and keys it in. The keyed-in check amount is added to the electronic record for that check.

Once entered into the system, multi-check deposits are compared with deposit slips automatically. When discrepancies arise, a worker whose title is "image balancer" tracks them down. Using images rather than paper checks, the image balancer performs the error detection and correction that was once one of the multiple tasks performed by the proof machine operator. ${ }^{14}$ But the job of image balancer, like other redesigned jobs, consists of a specialized task.

\section{c. The Demographics, Skills, and Wages of the Check-Processing Work Force}

The work force in check processing is more racially diverse today than 25 years ago but there has been little change in other dimensions. It is still primarily female. Most keyers, image balancers, and check preparers are high school graduates, as were proof machine operators in the past. Some long-time employees do not have high school diplomas. Many women with young children work twilight and night shifts, trading off childcare with husbands who have day-shift jobs. Some college students, who attend classes during the day at the nearby campus of the state university, work the twilight or night shift in check processing. They do the same work for the same pay as workers with less formal education.

\footnotetext{
14 The chief motivation for the new technology was cost reduction. In fact, Cabot Bank managers report that the average cost of image processing checks is greater than the cost of processing using proof machines. This comparison, however, is based on the Bank's conventions for allocating the substantial fixed costs associated with the introduction of the new technology. Marginal cost comparisons are not available. Due to these accounting conventions, we cannot say with certainty what happened to total factor productivity. It is clear, however, that labor productivity in Cabot Bank's check processing department has increased over the last decade.
} 
While workforce demographics are relatively constant, the introduction of the image and OCR technologies has resulted in an unbundling of the proof machine operator's tasks. Some of these tasks are performed by computers and the remaining tasks are divided among specialized jobs. More specialized jobs have led, in turn, to a modest increase in wage dispersion.

Both specialization and wage dispersion are displayed in Table 1. The first column lists the tasks that proof machine operators did in 1988. The second column describes how difficult it is to program computers to accomplish each task and how difficult it is for humans to do the work. The third column lists how each task was accomplished in 1998 (after the introduction of the image technology). The fourth column lists the number of people (in FTEs) employed in the position at Cabot Bank's central check processing location. The fifth column lists the 1998 hourly pay rate for each position.

Table 1 illustrates two points. First, the tasks proof machine operators carried out before the introduction of image processing have been divided into four jobs, one of which is carried out by computers and three by humans. Second, the wage associated with each of the three different jobs carried out by humans depends on the scarcity among humans of the relevant skills. Removing staples and ensuring that checks all face in the same direction are tasks most adults with normal eye-hand dexterity can accomplish. Consequently the hourly pay for this job, $\$ 9.51$, is the lowest among jobs in the bank's two departments.

The job of image balancing requires somewhat greater skills. Like the earlier proofing machine operator, the image balancer must be able to discover why some deposits do not balance. In addition, where the proofing machine operator worked with paper, the image balancer must know how to use computers and how to do the work using electronic images instead of paper checks. The Cabot vice president in charge of the department worked to recruit 
as many image balancers as possible from former proof machine operators, persons who had already demonstrated the requisite problem solving skills. The bank provided 36 hours of classroom training followed by two weeks of support from an experienced image balancer. ${ }^{15}$ In the end, most proof machine operators made the transition, suggesting that modest amounts of training could impart the requisite computer skills. In 1998, the average pay of the 62 image balancers was $\$ 11$ per hour, 16 percent higher than the pay rate for check preparers. The wage premium received by balancers reflected the relative scarcity of the skills required to do this job in the labor market in which Cabot Bank operated.

The department's highest wages were paid to the best keyers. While check preparers and image balancers were paid on an hourly rate, keyers were paid an hourly rate plus an hourly bonus based on speed and accuracy. A keyer's speed could now be monitored by computer, a feature that simplified bonus determination. Counting the bonus, the best keyers earned $\$ 13.50$ an hour, $\$ 2.00$ per hour more than image balancers. This relatively high wage reflected a return to the skill of being able to recognize and record check amounts extremely rapidly and accurately. ${ }^{16}$ As one bank official said, "there is always a demand for good keyers." In fact, "always" is too strong. Due to improvements in OCR software, a growing fraction of checks are read without human intervention. A result is that the demand for keyers at the bank per million checks processed has declined.

\section{d. The Impacts of Technological Change on Deposit Processing}

The introduction of image processing and OCR software led to the replacement of high school graduates by computers. At Cabot Bank the impact was muted because acquisitions led to

\footnotetext{
${ }^{15}$ Training began with playing games on the computer to develop facility in using a mouse. Substantial time was devoted to helping make the transition from working with paper checks to working with images of checks.

${ }^{16}$ The bank faces a strong incentive to hire and reward workers who can key rapidly since this reduces the number of keying workstations that the bank has to purchase and maintain.
} 
rapid growth during the 1990s in the number of checks processed. Consequently the 27 percent increase in average labor productivity between 1994 and 1999 was accomplished without layoffs. ${ }^{17}$ Thus, the technological change did result in the substitution of capital for relatively low skilled labor (high school graduates) in deposit processing. It is accurate to say that the technological changes in deposit processing were 'skill biased' since by displacing a group of less skilled workers, they increased the employment share of workers with more formal education. In this example, however, a more succinct statement is that computer capital substituted for less skilled workers in carrying out particular tasks.

Image processing also permitted a more extensive division of labor in deposit processing by reducing the transaction costs of moving information from one person to another. The work formerly done by proof machine operators was divided into four sets of specialized tasks, three of which were accomplished by humans. Proof machine operators who became image balancers already knew how to balance, since this had been part of the proofing job. They did need to learn to use personal computers and to work with digital images instead of paper. However, a few weeks of training allowed most to make the transition. As described in the next section, image processing led to a more dramatic impact on skill requirements in Cabot Bank's Exception Processing department.

In the future, computer-labor substitution in deposit processing is likely to increase. Further improvements in OCR software are one reason. A second concerns potential changes in regulations governing paper checks. State regulations currently dictate that bank customers can demand return of their cancelled paper checks at the end of each month. Currently, two-thirds of the bank's customers choose this option. Federal reserve regulations require that paper checks

\footnotetext{
${ }^{17}$ In 198867 workers in deposit processing processed one million checks per night. In 1998, 148 workers processed 2.8 million checks per night.
} 
written by Cabot Bank customers on other banks be returned. Changes in regulations permitting banks to provide customers with paper images of their checks and other banks with digital images of checks would eliminate the jobs of many low skilled workers who package checks for transit to customers and other banks.

Image processing may ultimately have an impact on the geographic location of deposit processing services. Since image keyers work with digital images, not paper checks, there is no technological reason why image keying needs to be accomplished at the site where the checks are digitized. Competitive pressure may push much of the back office clerical work to low wage offshore locations with a significant loss of jobs for less educated workers in the parent plant. ${ }^{18}$ One can currently see this geographic dispersion in other industries.

\section{Exceptions Processing}

More than ninety-seven percent of the 2.8 million checks deposited each day at Cabot Bank branches and ATMs are processed routinely. About 65,000 checks each day require individual attention. These are the "exceptions."

An exception arises when customers use checks from accounts they closed years ago or checks on which their account numbers are incorrectly printed. An exception arises when a branch teller misreads the account number written on a deposit slip. Other exceptions arise when customers overdraw their account or make stop payment requests or request a "caution" in which the bank is asked to look for checks that might have been stolen. Finally, there is fraud employees of a company steal blank checks and forge the signature of an authorized company

\footnotetext{
${ }^{18}$ One bank, Sun Trust, which operates in the southeastern part of the country, has already moved its keying operation to a central site. On recognizing that its keying operation outside Atlanta was particularly efficient, it transmits the images of checks from many processing sites to the Atlanta site for keying. There is no technological reason why the keying site could not be in another country. Examples like these suggest the difficulty in separating out "trade" and "technology" as distinct causes of declining demand for less educated workers.
} 
officer. Exceptions must be resolved rapidly both to satisfy Federal Reserve rules for returned checks and to provide good customer service.

\section{a. The Paper-Based System}

Ten years ago, exceptions processing was divided into a large number of narrowly defined jobs. For example, an employee who verified signatures on checks written for amounts greater than $\$ 2,000$ first found the authorized signature card in a file. She then compared the signature to the signature on the check and if a discrepancy appeared, filed a paper form that led to further action by a worker with greater decision making authority. A check could pass through three or four levels before reaching someone with the authority to make a final decision. Another group of workers processed stop payment orders, and still another group handled checks returned for insufficient funds. In each case, a significant proportion of the day was spent shuffling paper to find the right checks in a box of newly delivered items or to move checks from one group to another. Since all work was done under deadline, it created substantial employee frustration.

Female high school graduates filled most of the jobs in exceptions processing. In line with the low-skilled, repetitive nature of the jobs, pay was modest, approximately $\$ 10$ an hour (in 1998 \$). Turnover was 30 percent per year, tolerable only because the skills required were modest and could be learned quickly. Workers who stayed in exceptions processing developed expertise in one task, but had little knowledge of the work outside their immediate area. As one manager commented, "We were in a situation where people checked their brains at the door."

As the daily volume of checks rose, the cumbersome workflow created both increasing delays and poor customer service. For example, some customers who were short of cash would buy time by writing multiple checks to creditors and then issuing multiple stop payment requests. Depending on the timing, each check might trigger an overdraft exception as well as the stop payment exception. If a check was large enough, it also would trigger a signature verification 
exception. Each of the three clerks involved would have only a partial picture of the problem and each would have to locate the same paper check (in a large box of checks) to complete her processing. In the end, the customer might be (incorrectly) charged both a stop payment fee and an overdraft fee. If the customer went to a bank branch to resolve the situation, there was no single person in exceptions processing for the bank to call.

\section{b. New Technology}

The vice president used the anticipated arrival of check imaging to consider how exceptions processing could be reorganized. He believed the reorganization could achieve some measure of three goals: better customer service, improved productivity, and redesigned jobs that would use more skills. In his words, he wanted "fewer people doing more work in more interesting jobs."

In exceptions processing, like deposit processing, the introduction of image processing lowered the time and cost of transferring information. Clerks in exceptions processing no longer had to wait for boxes of paper checks to be delivered to their desks. Since a clerk could access check images from a personal computer networked to the bank's mainframe, she could concentrate on resolving exceptions instead of devoting considerable time looking for paper checks. The vice president understood that fully exploiting this advantage would require a redesigned workflow. He also believed that involving current employees in the redesign would both utilize their knowledge and gain their commitment to the new system.

Managers held focus groups of exceptions processing clerks, asking them what aspects of their jobs were irritating, and what changes would make the jobs better. The consensus of these meetings was that work should no longer be divided by exception type but by customer account,

\footnotetext{
19 The goal of making jobs more interesting is consistent with Lindbeck's and Snower's observation that one factor driving workplace redesign is changes in tastes accompanying increased education of the workforce (Lindbeck and Snower, 2000).
} 
so that the same representative would deal with all exceptions - stop payment requests, overdrafts, etc. - connected to the given account. In this way, for example, a clerk who saw a stop payment-order would anticipate a possible (incorrect) overdraft exception as well as other stop payment and overdraft exceptions from the same account.

This reorganization would not be cost-free. A representative who had processed one type of exception for a number of years would now have to learn how to process a variety of exceptions. She would require training to learn how to do her work on a networked personal computer rather than with paper. Nonetheless, management accepted the plan.

In deposit processing, the lowered transactions costs of moving information led to a greater division of labor with the proof machine operator's job broken into several specialized jobs. In exceptions processing, the introduction of check imaging led to the opposite result: narrow jobs were combined into new, broader jobs with responsibility for handling a variety of exceptions for a block of accounts. Differences between the work in the two departments explain the difference in work re-organizations.

In exceptions processing, tasks had a clear sequence, beginning with checks entering the department, and ending with checks leaving the department. There was little room to alter the sequence. One of the tasks, "reading" and recording the amounts on legible checks, could be accomplished with considerable cost savings by computers, and it was possible to electronically send illegible checks to image keyers who specialized in reading and recording their values.

In exceptions processing, the challenge was to re-organize the work so as to improve customer service and reduce processing costs. This required taking advantage of the interdependencies among exceptions for the same account. Department employees felt strongly 
that this integration was impossible as long as pieces of the customer's problem were assigned to different people.

While the account-based workflow was designed in anticipation of check imaging, the bank began implementation before imaging technology came on line. The immediate result $-\mathrm{a}$ surprise to managers - was a major improvement in productivity. Before the re-organization, 650 workers processed the 65,000 exceptions each day. By the end of 1995, after the re-organization of exceptions processing, but before the introduction of the image technology, this same workload was completed by 530 workers. ${ }^{20}$

As long as the process relied on paper significant bottlenecks remained. Clerks were still spending considerable time shuffling paper checks. Answering a query from a branch bank still involved a search for the right paper check. Check imaging removed most of these obstacles. By the end of 1996, a year after the introduction of the image technology, the number of workers in exceptions processing had fallen to $470 .{ }^{21}$ Ultimately, reorganization accounted for about twothirds of productivity gains with technology accounting for the other one-third. ${ }^{22}$

Because exceptions processors now had more extensive training to handle a wider variety of tasks, and their new skills were also valued by competitors, management decided it was prudent to pay higher wages. In 1993, before the reorganization of exceptions processing, 80 percent of the workers were classified as "non-exempt" (i.e. their jobs did not require working

\footnotetext{
${ }^{20}$ Employees engaged in an 80 hour round of initial training - 40 hours in the classroom and 40 hours on the job to learn the skills needed to handle the full range of exceptions.

${ }^{21}$ The acquisition of another bank has led to a subsequent increase in the number of exceptions processed by the bank and the number of employees in exceptions processing.

${ }^{22}$ Given the productivity gains that Cabot Bank realized from re-organizing exceptions processing before the introduction of the image technology, we wondered whether the Bank had considered undertaking this reengineering during the late 1980s when check volume was rising. A manager responded that the bank was focused on absorbing newly acquired banks and did not consider the re-organization of exceptions. The manager also stated that other banks that do not use image processing still organize exceptions processing as a group of narrowly defined jobs. It is possible, though by no means certain, that the fixed costs of account-based reorganization were sufficiently large that they only became attractive when imaging technology would leverage the productivity gains.
} 
independently, showing initiative or supervising others.) These non-exempt workers averaged $\$ 10.64$ an hour on average (in 1998 \$). In 1998, average wages in the unit were $\$ 13.50$. Most workers were moved up a pay grade as a result of successfully completing training. In addition, management steadily increased the proportion of representatives who were "exempt", reflecting their new responsibilities. By 1998, 35 percent of the unit was in this category.

Management also expanded the range within each pay grade. For example, the pay range in grade 23 - a grade to which many representatives were initially assigned - had a 1993 range of $\$ 17,829$ to $\$ 26,332$ but a 1998 range of $\$ 18,900$ - $\$ 37,100$ (all figures expressed in $1998 \$$ ). The greater pay range reflected employees' greater scope for judgment and initiative in the redesigned job. In particular, Cabot was one of the first banks to reorganize exceptions processing using check imaging and management believed that motivated employees could recommend additional improvements. As the vice president said "If you do your job, you get to keep your job -- but you may not get cost-of-living wage increases. If you transform your job in a positive way, you will get a raise. If you transform your job and have a positive impact on the people around you, you will get a promotion."

\section{c. The Impacts of Technological Change on Exceptions Processing}

The story of computerization in exceptions processing illustrates two patterns identified in quantitative studies of the consequences of computer-based technological changes. The first is the loss of jobs held by high school graduates. Between 1994 and 1996, the workforce needed to process 65,000 exceptions a night fell by 28 percent. A significant part of this reduction came through reorganization undertaken in anticipation of imaging technology rather than imaging technology per se. But this process - technology acting as a stimulus to reorganizing work routines - is likely to have occurred in many other industries and so may influence patterns in the 
CPS and other data sets. At Cabot Bank, high turnover in exceptions processing meant workforce reduction did not require layoffs; but over the period 180 positions were eliminated, almost all of them formerly held by high school graduates. ${ }^{23}$

A second pattern is a direct positive impact on skill demands. Reorganization of work and the introduction of the image technology increased the skills needed in exceptions processing. Training went a long way toward increasing the supply of skills, especially computer skills. Managers reported, however, that the more difficult skill to teach was the ability to "see the whole picture," that is, understand the sequence of steps in processing a check and recognize the interdependencies among exceptions.

Because "seeing the whole picture" proved hard to teach, Cabot Bank managers restructured recruiting processes to attract more employees who had this skill and wanted to use it. Under the revised recruiting procedures, managers asked candidates to describe problems they had encountered in previous jobs or in school and how they resolved them. The intent was to identify candidates who had a history of initiative and problem-solving. In addition, candidates were interviewed by supervisors from several groups. They could be hired into a group only if supervisors from two other groups agreed that the person would be a good new hire. In the words of one manager, recruits "have to be right for the whole bank; not just for my area." Managers reported that, with exceptions, the new recruiting process seemed to favor applicants who had completed college.

This increased demand for educated workers had two identifiable sources. First, in the redesigned department, computers consolidate all of the relevant account information and present it directly to the exceptions processor. This job design places a premium on the problem solving

\footnotetext{
${ }^{23}$ In addition, to the extent that computers directly substitute for tasks performed by high school graduates, price declines in computer technology place downward pressure on high school graduate wages independent of any
} 
skills needed to make appropriate decisions rapidly. Second, in the ongoing process of workplace redesign, college-educated workers tended to excel at making suggestions for further process improvements. The observation that college graduates are better able to function in settings undergoing change is consistent with the work of (Nelson and Phelps, 1966), (Schultz, 1975), and (Welch, 1970).

\section{Conclusions}

Making use of the image processing technology introduced in 1994 is an ongoing process. For example, the bank has started to produce compact disks containing images of all of the checks written by and received by corporate customers during a month. These customers value the CDs both because they simplify storage and sharply reduce search costs when responding to customer and vendor billing queries. Ultimately, this switch to CDs will reduce customers' need for filing jobs - jobs typically held by persons who have not gone beyond high school.

The bank also plans to take advantage of dramatic cost reductions in storage devices to electronically store the images of its customers' checks. Eventually, customers will be able to receive services including going to a web site to see whether particular checks have cleared, a trend that will reduce demand for customer service representatives. The bank is also planning to use information on check writing patterns to better target marketing of investment services, information that can complement interpersonal sales skills. All of these developments suggest that this paper describes only the short term consequences of the technological change introduced in 1994.

By describing how a particular technological change played out in two departments of a large bank, this case study illustrates four points. First, it indicates that the same technological change

employment effects (Autor, Levy, and Murnane, 2000). 
can result in computer-labor substitution, as it did in deposit processing, and in computer-skill complementarity, as it did in exceptions processing. While both of these forces lead to relative employment gains for educated workers, they are, as the case illustrates, distinct. ${ }^{24}$ Second, the case underscores the interdependence of technological change and organizational change, a theme emphasized by (Bresnahan, Brynjolfsson and Hitt, 1999), (Caroli and Van Reenen, 1999), (Goldin and Katz, 1998), and (Lindbeck and Snower, 2000). Third, it suggests that "seeing the whole picture" and associated conceptual and problem-solving skills are one set of skills made more valuable by information technologies. Finally, the case illustrates that the short term consequences of technological changes may depend critically on regulatory changes, although in the long run, these regulatory forces may also be influenced by technological and economic opportunities.

\footnotetext{
${ }^{24}$ Autor, Levy and Murnane, 2000 formally investigate the importance of these two forces (computer-labor substitution and computer-skill complementarity).
} 


\section{Table 1}

\begin{tabular}{|c|l|c|c|c|}
\hline $\begin{array}{c}\text { Tasks done by 67 proof } \\
\text { machine operators in 1988 } \\
\text { at an hourly wage rate (in } \\
\mathbf{1 9 9 8} \text { \$) of \$10.03 }\end{array}$ & $\begin{array}{c}\text { Extent to which task is } \\
\text { "routine" from a } \\
\text { programming perspective }\end{array}$ & $\begin{array}{c}\text { How tasks } \\
\text { were } \\
\text { carried out } \\
\text { in 1998 }\end{array}$ & $\begin{array}{c}\text { Number of } \\
\text { Workers } \\
\text { in 1998 }\end{array}$ & $\begin{array}{c}\text { 1998 } \\
\text { Hourly } \\
\text { Wage }\end{array}$ \\
\hline $\begin{array}{c}\text { A. Preparing checks } \\
\text { Non-routine optical } \\
\text { recognition and motor control } \\
\text { - difficult to program but not } \\
\text { challenging for workers. }\end{array}$ & $\begin{array}{l}\text { Check } \\
\text { preparers }\end{array}$ & 45 & $\$ 9.51$ \\
\hline $\begin{array}{c}\text { B. Keying in amount on } \\
\text { checks with clear printing } \\
\text { or handwriting }\end{array}$ & $\begin{array}{l}\text { Routine optical scanning - } \\
\text { easily done by computers or } \\
\text { workers but computers are } \\
\text { more cost effective }\end{array}$ & Computer & 0 & \\
\hline $\begin{array}{c}\text { C. Deciphering amounts } \\
\text { handwriting and keying in } \\
\text { the amount }\end{array}$ & $\begin{array}{l}\text { Non-routine optical } \\
\text { recognition - difficult to } \\
\text { program but not challenging } \\
\text { for workers. }\end{array}$ & Keyers & 41 & $\begin{array}{c}\text { \$10 plus } \\
\text { incentives } \\
\text { for speed \& } \\
\text { accuracy }\end{array}$ \\
\hline $\begin{array}{c}\text { D. Balancing the deposit } \\
\text { Non-routine search for error } \\
\text { sources. Hard to program, } \\
\text { relatively challenging for } \\
\text { workers. }\end{array}$ & $\begin{array}{l}\text { Image } \\
\text { balancers }\end{array}$ & 62 & \$11.00 \\
\hline
\end{tabular}




\section{References}

Autor, David, Lawrence F. Katz, and Alan B. Krueger. 1998. "Computing Inequality: Have Computers Changed the Labor Market?” Quarterly Journal of Economics 113:11691213.

Autor, David H., Frank Levy, and Richard J. Murnane. 2000. "The Skill Content of Recent Technological Change: An Empirical Exploration." Paper presented at the National Bureau of Economics Research Summer Labor Economics Workshop .

Berman, Eli, John Bound, and Zvi Griliches. 1994. "Changes in the Demand for Skilled Labor within U.S. Manufacturing Industries: Evidence from the Annual Survey of Manufactures." Quarterly Journal of Economics 109:367-97.

Berman, Eli, John Bound, and Stephen Machin. 1998. "Implications of Skill-Biased Technological Change: International Evidence." Quarterly Journal of Economics 113:1245-79.

Bresnahan, Timothy F., Erik Brynjolfsson, and Lorin M. Hitt. 1999. "Information Technology, Workplace Organization and the Demand for Skilled Labor: Firm-Level Evidence." National Bureau of Economic Research Working Paper No. W7136 .

Caroli, Eve, and John Van Reenen. 1999. "Skill-Biased Organizational Change? Evidence from a Panel of British and French Establishments." CEPREMAP Working Paper 9917.

Caselli, Francesco. 1999. "Technological Revolutions." American Economic Review 89:78102.

Feldstein, Martin. 2000. "Preface: The NBER-Sloan Project on Productivity Change." in Industrial Technology and Productivity: Incorporating Learning from Plant Visits and Interviews into Economic Research. Cambridge, Ma: National Bureau of Economic Research.

Goldin, Claudia, and Lawrence F. Katz. 1998. "The origins of Technology-Skill Complementarity." Quarterly Journal of Economics 113:693-732.

Katz, Lawrence F., and Kevin M. Murphy. 1992. "Changes in Relative Wages, 1963-87: Supply and Demand Factors.” Quarterly Journal of Economics 107:35-78.

Levy, Frank, Anne Beamish, and Richard J. Murnane. 1999 "Computerization and Skills: Examples from a Car Dealership”, mimeo, MIT Department of Urban Studies and Planning, November.

Lindbeck, Assar, and Dennis J. Snower. 2000. "Multitask Learning and the Reorganization of Work: From Tayloristic to Holistic Organization.” Journal of Labor Economics 18:353-76. 
Machin, Stephen, and John Van Reenen. 1998. "Technology and Changes in Skill Structure: Evidence from Seven OECD Countries.” Quarterly Journal of Economics 113:1215-44.

Mayer, Martin. 1997. The Bankers. New York: Truman Valley Books/Plume.

McKenney, James L. 1995. Waves of Change: Business Evolution through Information Technology. Boston: Harvard Business School Press.

Nelson, Richard R., and Edmund S. Phelps. 1966. "Investment in Humans, Technological Diffusion, and Economic Growth." American Economic Review 56.

Orr, J.E. (1996). Talking About Machines: An Ethnography of a Modern Job. Ithaca: ILR Press.

Pinker, Steven. 1997. How the Mind Works. New York: W.W. Norton.

Polanyi, Michael. 1966. The Tacit Dimension. New York: Doubleday.

Rifkin, Jeremy. 1995. The End of Work: The Decline of the Global Labor Force and the Dawn of the Post-Market Era. New York: G.P. Putnam's Sons.

Schultz, Theodore W. 1975. "The Value of the Ability to Deal with Disequilibria." Journal of Economic Literature 13:827-846.

Welch, Finis. 1970. “Education in Production.” Journal of Political Economy 78:35-59.

Wolff, Edward N. 1996. "The Growth of Information Workers in the U.S. Economy, 195090: The Role of Technological Change, Computerization, and Structural Change." C.V. Starr Center for Applied Economics, New York University RR\#96-41 .

Zuboff, Shoshona. 1988. In the Age of the Smart Machine. New York: Basic Books. 